\title{
Synthesis of functionalized fluorescent silver nanoparticles and their toxicological effect in aquatic environments (Goldfish) and HEPG2 cells
}

\section{Elisabete Oliveira ${ }^{1,2 *}$, Hugo M. Santos ${ }^{1}$, Javier Garcia-Pardo ${ }^{3}$, Mário Diniz' ${ }^{1}$, Julia Lorenzo ${ }^{3}$, Benito Rodríguez-González ${ }^{4}$, José L. Capelo ${ }^{1}$ and Carlos Lodeiro ${ }^{1 *}$}

\author{
${ }^{1}$ Bioscope Group, REQUIMTE, Chemistry Department, Faculty of Science and Technology, University Nova of Lisbon, Lisbon, Portugal \\ ${ }^{2}$ Veterinary Science Departments, CECAV, University of Trás-os-Montes and Alto Douro, Vila Real, Portugal \\ ${ }^{3}$ Institut de Biotecnologia i Biomedicina and Departament de Bioquímica i de Biologia Molecular, Universitat Autònoma de Barcelona, Bellaterra, Barcelona, Spain \\ ${ }^{4}$ Scientific and Technological Research Assistance Centre (CACTI), University of Vigo, Vigo, Spain
}

Edited by:

Luís A. D. Carlos, University of

Aveiro, Portugal

Reviewed by:

Jun Lin, Chinese Academy of

Sciences, China

Iztok Turel, University of Ljubljana,

Slovenia

\section{*Correspondence.}

Elisabete Oliveira and Carlos

Lodeiro, Bioscope Group,

REQUIMTE, Chemistry Department,

Faculty of Science and Technology,

University Nova of Lisbon, Caparica

Campus, 2825-366 Lisbon, Portugal

e-mail: ej.oliveira@fct.unl.pt;

cle@fct.unl.pt
Silver nanoparticles, AgNPs, are widely used in our daily life, mostly due to their antibacterial, antiviral, and antifungal properties. However, their potential toxicity remains unclear. In order to unravel this issue, emissive AgNPs were first synthetized using an inexpensive photochemical method, and then their permeation was assessed in vivo in goldfish and in vitro in human hepatoma cells (HepG2). In addition, the oxidative stress caused by AgNPs was assessed in enzymes such as glutathione-S-transferase (GST), catalase (CAT), and in lipid peroxidation (LPO). This study demonstrates that the smallest sized AgNPs@3 promote the largest changes in gold fish livers, whereas AgNPs@1 were found to be toxic in HEPG2 cells depending on both the size and functionalized/stabilizer ligand.

Keywords: silver nanoparticles, fluorescence, cytotoxicity, goldfish, human hepatoma cells

\section{INTRODUCTION}

Silver nanoparticles (AgNPs) have gained momentum due to their use in imaging, catalysis, electronics, photonics, and photography (Evanoff and Chumanov, 2005; Dahl et al., 2007; Liang et al., 2007; Pastoriza-Santos and Liz-Marzán, 2008). In addition, medical devices and therapeutic products containing AgNPs also offer health benefits, such as antibacterial, antiviral, and antifungal properties. Because of such properties, AgNPs are of the focus of precautions and regulations related to public health and environmental risks (Faunce and Watal, 2010). In the USA there are more than 260 commercialized products containing AgNPs, such as cleaners, clothing, and personal care products (Faunce and Watal, 2010). Silver itself is known to be highly toxic in cells, but AgNP toxicity still has been target of studies. AgNPs can form protein-silver complexes, which according to in vitro studies, can be deposited in the liver, kidney, lungs, brain, and/or skin, as they are highly toxic to mammalian liver cells, stem cells, and brain cells (Hussain et al., 2005; Landsdown, 2007).

The US National Institute for Occupational Safety and Healthy (NIOSH) has established an exposure limit of $0.01 \mathrm{mg} / \mathrm{m}^{3}$ for all forms of silver (Drake and Hazelwood, 2005). In 2010, nanosilver was considered one of the 15 issues that can negatively affect the conservation of biological diversity (Sutherlandm et al., 2010). The experts are concern about the wide use of nanosilver, not mainly because of the direct poisoning in humans or production of bacterial resistance in hospital setting, but due to their highly in vitro toxicity for aquatic organisms and capability to persist in the environment. Silver and its forms can be release in the environment into waste streams, such as from photographic development, which has been the major source of ecological toxicity (Luoma, 2008).

Toxicological studies of Ag nanoparticles with different diameters, 36, 52, and $66 \mathrm{~nm}$ have been reported in freshwater environments through the use of Daphnia magna. It was found that within the concentration range of $3-4 \mu \mathrm{g} / \mathrm{L}$, toxicity is not sizedependent (Li et al., 2010). Comparative studies of gold and AgNPs reveal that the silver ones are the most toxic (Hussain et al., 2005). Regarding AgNP synthesis, the most common and straightforward approach is based on reductive methods, using sodium borohydrate, sodium citrate, or irradiation (Lee and Meisel, 1982; Chau et al., 2005). To avoid particle aggregation, this is often done in the presence of additives such as organic molecules, peptides (Lodeiro et al., 2010; Oliveira et al., 2011a,b), or polymers. Usually metal nanoparticles do not present fluorescence emission, due to the electron transfer from the AgNP metal core to the additive.

On the other hand in some cases, the presence of other types of additives in the surrounding AgNPs enhances their photophysical properties, such as luminescence (Tam et al., 2007). Research into fluorescent nanoparticles has thus, increased steadily in the last few years, because fluorescence can be traced in vivo and in vitro (Alivisatos, 1996). AgNPs exhibit an intensive surface plasmon resonance (SPR) band, due to the collective oscillation of the electrons, in the wavelength range of 300-900 nm (Díez et al., 2009). 
The localization of the SPR band depends on several parameters, such as, size, shape and the refractive index of the environment (Si et al., 2007; Belser et al., 2009).

Maretti et al. (Maretti et al., 2009) published a new easy method based on the photochemical synthesis of fluorescent AgNPs, which can be used in imaging applications. In Maretti's method, the AgNPs were stabilized by cyclohexylamine, and the metal is reduced by ketyl radicals.

For "Proof of Concept" of the study viability in a complex organism and in cell cultures, AgNP permeation and toxicity were carried out in vivo in gold fish (Carassius auratus), whilst cytotoxicological studies were performed in vitro in human hepatoma cells. AgNPs were synthetized with a new easy and inexpensive method, which was developed by varying Maretti's method (Maretti et al., 2009), using (1) 5-Aminoisoquinoline, (2) 7-amino-4-methylcoumarin, and (3) 2-Aminoanthracene as additives. AgNP formation was monitored by UV-Vis and fluorescence emission spectroscopy, matrix-assisted laser desorption ionization time of flight mass spectrometry (MALDI-TOF MS), dynamic light scattering (DLS), transmission electron microscopy (TEM), and high-resolution transmission electron microscopy (HRTEM).

\section{MATERIALS AND METHODS CHEMICALS AND STARTING MATERIALS}

5-Aminoisoquinoline, 7-amino-4-methylcoumarin, and 2Aminoanthracene, 2-Hydroxy-4'-(2-hydroxyethoxy)-2-methylpropiophenone (I-2959) were commercially from Aldrich. $\mathrm{Ag}\left(\mathrm{CF}_{3} \mathrm{SO}_{3}\right)$ was from Fluka. All were used without further purification.

\section{PHYSICAL MEASUREMENTS Instruments}

The samples were exposed to ultraviolet light at $365 \mathrm{~nm}$, in a common UVA lamp, 230 V, 50 Hz, Serial n MO31975, Ambientáls.

\section{Particles size distribution}

The nanoparticle size distributions were measured using DLS, a Malvern Nano ZS instrument with a $633 \mathrm{~nm}$ laser diode.

\section{TEM measurements}

To perform the TEM images, the samples were prepared by dropping $1 \mu \mathrm{L}$ of the colloidal suspension onto a copper grid coated with a continuous carbon film and allowing the solvent to evaporate. TEM and HRTEM images were obtained using a JEOL JEM 2010F transmission electron microscope (TEM) operating at $200 \mathrm{kV}$. To perform the Fourier transformations, we used Digital Micrograph (Gatan) software. Data for size distribution histograms were obtained by measuring more than 100 particles per sample in several TEM images (Saìnchez-Iglesias et al., 2006).

\section{MALDI-TOF-MS studies}

The MALDI-MS analyses were performed in a MALDI-TOFTOF-MS model Ultraflex II Bruker, Germany, equipped with nitrogen. Each spectrum represents accumulations of $5 \times 50$ laser shots. The reflection mode was used. The ion source and flight tube pressure were less than $1.80 \times 10^{-7}$ and $5.60 \times 10^{-8}$ Torr, respectively. The MALDI mass spectra of the soluble samples ( 1 or $2 \mu \mathrm{g} / \mu \mathrm{L}$ ) were recorded using the conventional sample preparation method for MALDI-MS. $1 \mu \mathrm{L}$ of ligand was placed on the sample holder. The sample holder was inserted in the ion source.

\section{Photophysical measurements}

Absorption spectra were recorded on a JASCO V-650 spectrophotometer and fluorescence emission on a FLUOROMAX-4 HORIBA SCIENTIFIC spectrofluorometer.

\section{Synthesis of silver nanoparticles}

In an quartz cell $1.02 \times 10^{-2} \mathrm{M}$ of I-2959, $3.4 \times 10^{-3} \mathrm{M}$ of $\mathrm{Ag}\left(\mathrm{CF}_{3} \mathrm{SO}_{3}\right)$, and $2.0 \times 10^{-4} \mathrm{M}$ of compounds 1,2 , or 3 , were added to a $3 \mathrm{~mL}$ of THF solution. The spectral changes were observed upon irradiation. Thereafter, the nanoparticles obtained were washed several times by centrifugation, in order to remove the unreacted products.

\section{Cell culture}

Human hepatocellular carcinoma HepG2 cell line (ATCC HB8065), derived from human hepatocytes, was maintained in a Minimum Essential Medium (MEM) alpha medium supplemented with $10 \%(\mathrm{v} / \mathrm{v})$ heat inactivated fetal bovine serum (FBS) in a highly humidified atmosphere of $95 \%$ air with $5 \%$ $\mathrm{CO}_{2}$ at $37^{\circ} \mathrm{C}$.

\section{Cytotoxicity of the AgNPs}

The cytotoxicity of AgNPs (1, 2, and 3) was tested in human HepG2 cells. Cells were seeded into a 96-well plate at a cell density of $6.0 \times 10^{3}$ cell/well and incubated for $24 \mathrm{~h}$ before AgNPs were added at a concentration of 25 and $100 \mu \mathrm{g} / \mathrm{ml}$. The growth inhibitory effect was measured after $72 \mathrm{~h}$ treatment by the XTT assay (Cory et al., 1991; You et al., 2012). Aliquots of $20 \mu \mathrm{l}$ of XTT solution [2,3-bis-(2-methoxy-4-nitro5-sulfophenyl)-2H-tetrazolium-5-carboxanilide] were added to each well. After $3 \mathrm{~h}$, the color formed was quantified by a spectophotometric plate reader (Perkin Elmer Victor ${ }^{3}$ V) at a $490 \mathrm{~nm}$ wavelength. Cell cytotoxicity was evaluated in terms of cellgrowth inhibition in treated cultures and expressed as a \% of the control conditions. Trypan Blue is one of the many dye recommended exclusion staining, counting and evaluation of cellular population and acute cellular toxicity (Wong et al., 2006) techniques. This method is based on the principle that the living cells do not incorporate the dye, whereas dead cells incorporate it owing to their damaged membrane. Cells treated with $100 \mu \mathrm{g} / \mathrm{ml}$ concentration of AgNPs for $72 \mathrm{~h}$ were rinsed with PBS, stained with $0.2 \%$ Trypan Blue (Invitrogen) for $5 \mathrm{~min}$ and observed by microscopy.

\section{CLSM in vivo imaging of AgNP-Treated HEPG2 cells}

HepG2 cells were seeded at a density of about $2 \times 10^{5}$ cells per plate on $14 \mathrm{~mm}$ glass bottom microwell dishes (MatTek, corp). After $24 \mathrm{~h}$ cells were treated with 25 and $100 \mu \mathrm{g} / \mathrm{ml}$ of AgNPs $(1,2$, and 3$)$ and incubated for $24 \mathrm{~h}$. At the end of incubation, cells were washed three times with media and stained for $7 \mathrm{~min}$ with Hoechst (Invitrogen) and CellMask red (Invitrogen) at $37^{\circ} \mathrm{C}$. 
Imaging was performed immediately at $37^{\circ} \mathrm{C}$ and $5 \% \mathrm{CO}_{2}$ on a Leica TCS SP5 confocal microscope using a $63 \times 1.4$ numerical aperture Plan Apochromat oil-immersion lens. Acquired images were processed using Bitplane Imaris 7.2.1 software.

\section{Flow cytometry of AgNP-treated cells}

The cellular uptake of $\operatorname{AgNPs}(\mathbf{1}, 2$, and 3) was carried out via flow cytometric measurements. To perform the experiments $3.0 \times 10^{5}$ HepG2 cells per plate were seeded in 6-well plates (BD Falcon). After $24 \mathrm{~h}$ treatments with 25 and $100 \mu \mathrm{g} / \mathrm{ml}$ of AgNPs $(1,2$, and 3), cells were collected and centrifuged. Cells were then rinsed and resuspended in $1 \mathrm{ml}$ of PBS. Flow cytometry analysis was performed with FACSCalibur flow cytometry at an emission wavelength of $488 \mathrm{~nm}$.

\section{In vivo studies}

Goldfish (Carassius auratus) were obtained from local producers $(N=6$ per treatment, average weight: $10.2 \pm 3.4 \mathrm{~g})$ and acclimated for 2 weeks to laboratory conditions in $400 \mathrm{~L}$ polystyrene. The fish were housed in a closed circuit system with filtered tap water at a temperature of $20 \pm 1^{\circ} \mathrm{C}, \mathrm{pH} 7.2 \pm 0.2$, and continuous aeration and fed daily with commercial feed flakes (TetraMin). Following synthesis, AgNps were injected in fish by an intraperitoneal injection to evaluate their ability of internalization in fish tissues. Thus, two assays ( $\mathbf{A}$ and $\mathbf{B}$ ) with a total of 24 animals were carried out. A-Intraperitoneal injection of AgNPs in PBS (1:10); B-Intraperitoneal injection of AgNPs diluted in corn oil (1:10). After injection, fish were maintained in $15 \mathrm{~L}$ polystyrene tanks, with de-chlorinated tap water, photoperiod 12:12 h light/dark (L/D and continuous aeration (dissolved $\mathrm{O}_{2}>6 \mathrm{mg} / \mathrm{L}$ ). Control fish were housed in the same laboratory conditions but were injected intraperitoneally with (a) a solution of PBS (phosphate buffer solution), (b) a solution of PBS and THF (1:10); and (c) a solution of PBS and corn oil (1:10). After $48 \mathrm{~h}$ fish, including controls, were sacrificed by cervical sectioning and dissected with the aid of scissors, a scalpel and forceps, and the liver and intestine removed. Samples from organs were stored at $-80^{\circ} \mathrm{C}$ for further analysis and other subsamples were taken for histological processing.

Total Glutathione-S-Transferase (GST) activity was determined as described by Habig et al. (Habig et al., 1974) by measuring the formation of the conjugate of glutathione (GSH) and 1-chloro-2,4-dinitrobenzene (CDNB). Briefly, $180 \mu \mathrm{L}$ of substrate solution (Dulbecco's Phosphate Buffered Saline with $200 \mathrm{mM}$ L-glutathione reduced and $100 \mathrm{mM}$ CDNB all from Sigma-Aldrich, Germany) were added to $20 \mu \mathrm{L}$ of GST standard or sample into each well of a 96-well microplate. The total enzyme activity was determined at $340 \mathrm{~nm}$ by recording the absorbance at every minute for $6 \mathrm{~min}$, using a microplate reader (BioRad Benchmark, USA). Equine liver GST (Sigma-Aldrich, Germany) was used as standard and positive control. The change in absorbance per minute $\left(\lambda \mathrm{A}_{340}\right)$ was estimated and the reaction rate at $340 \mathrm{~nm}$ was determined using CDNB extinction coefficient of $0.0096 \mu \mathrm{M}^{-1} \mathrm{~cm}^{-1}$. The results are expressed in relation to total protein concentration of the sample ( $\mathrm{mmol} \mathrm{min}^{1} \mathrm{mg}^{1}$ total protein).
Catalase(CAT) activity was determined as previously described by Aebi (Aebi, 1984), which follows the decrease in absorbance at $240 \mathrm{~nm}$ by $\mathrm{H}_{2} \mathrm{O}_{2}$ consumption. Briefly, A substrate solution of $0.036 \%(\mathrm{w} / \mathrm{w}) \mathrm{H}_{2} \mathrm{O}_{2}$ was prepared in buffer $50 \mathrm{mM}$ $\mathrm{KH}_{2} \mathrm{PO}_{4}$ (Sigma-Aldrich, Germany) pH 7.0 containing $1 \mathrm{mM}$ EDTA (Riedel-Haën, Germany), at $25^{\circ} \mathrm{C}$ using $30 \%$ (w/w) $\mathrm{H}_{2} \mathrm{O}_{2}$ (Sigma-Aldrich, Germany). To perform the assay, $0.1 \mathrm{~mL}$ of CAT standard or sample were added to $2.9 \mathrm{~mL}$ of the substrate solution in individual quartz cuvettes and absorbance at $240 \mathrm{~nm}$ was recorded every $30 \mathrm{~s}$ for $180 \mathrm{~s}$ (at $25^{\circ} \mathrm{C}, \mathrm{pH} 7.0$, and path length $10 \mathrm{~mm}$ ), using a spectrophotometer (Unicam Helios, UK). The consumption of peroxide was monitored using a extinction coeff. $0.04 \mathrm{mmol}^{-1} \mathrm{~cm}^{-1}$. Bovine liver CAT (Sigma-Aldrich, Germany) was used as standard and positive control.

Lipid peroxides assay adapted from TBARS (thiobarbituric acid substances) protocol was determined by the quantification of a specific end-product of the oxidative degradation process of lipids, the malondialdehyde (MDA). In this assay thiobarbituric acid reacts with MDA to produce a fluorescent product detected spectrophotometrically at $532 \mathrm{~nm}$. Briefly, samples were treated with $8.1 \%$ dodecyl sulfate sodium, $20 \%$ trichloroacetic acid ( $\mathrm{pH} 3.5)$, thiobarbituric acid, mixture of n-butanol and pyridine (15: 1, v/v) (Correia et al., 2003). To quantify the lipid peroxides, MDA concentrations were calculated with the computer program Microplate Manager 4.0 (BIO-RAD, USA) based on an eight-point calibration curve (0-0.3 $\mu \mathrm{M}$ TBARS) using MDA bis(dimethylacetal) (from Merck). The enzymatic results are expressed in relation to total protein of the sample ( $\mathrm{nmol} / \mathrm{min} / \mathrm{mg}$ ) calculated following the procedure described by Bradford (Bradford, 1976) using albumin as a standard.

The histological procedures were carried out essentially according to Martoja and Martoja (Martoja and Martoja, 1967). Briefely, after being fixed in Bouin-Hollande's for $48 \mathrm{~h}$, samples were washed in distilled water and dehydrated through a series of graded ethanol solutions and toluene (Lab-Scan, Belgium) for intermediate impregnation. Organs were embedded in paraffin (Panreac, Spain), cut in sections of $5 \mu \mathrm{m}$ thickness and mounted in glass slides. Paraffin was removed from slides using xylene as solvent, followed by rehydration in a graduate series of alcohols, washing with demineralized water, then glycine $(0.3 \mathrm{M})$ and staining ( $5 \mathrm{~min}$.) with toluidine blue-O $(0.5 \%)$ prepared from a solution of $\mathrm{NaBH}_{4}(1 \%)$ for further histological analysis. Staining with toluidine blue $\mathrm{O}$ allows quenching of auto-fluorescence and enhances the fluorescence of nano-emissive particles (Kiernan, 2008). The presence of emissive NPs within tissues was assessed using a Leica microscope (Leica-ATC 2000, Germany), with an image system from Leica Microsystems (DMLB model) adapted for epifluorescence and equipped with an EL6000 light source for mercury short-arc reflector lamps was used. For tissue microscope analysis I3 (blue) and N2.1 (green) filters were employed.

\section{Statistical analysis}

The results were expressed as the mean \pm SD. The statistics of enzymes activities were performed by the non-parametric test Kruskal-Wallis, with a significant level of $p<0.05$, using the software Statistica 8.0 (StatSoft Inc., USA). 


\section{RESULTS AND DISCUSSION}

The photosynthesis of the AgNPs was performed in a quartz cell followed by the addition of I-2959, $\mathrm{AgCF}_{3} \mathrm{SO}_{3}$, and the chromophore $(1,2$, or 3 ) in a THF solution, with subsequent exposure to a UVA lamp at $365 \mathrm{~nm}$. The I-2959 acts as a source of ketyl radicals, which are known to be strong reducing agents, allowing the reduction of silver ions in the presence of (1) 5-Aminoisoquinoline, (2) 7-amino-4-methylcoumarin, and (3) 2-Aminoanthracene (see Figure 1). The chosen compounds 1-3 have all their absorption spectrum in the UV region, since the lamp used for photochemical synthesis via irradiation was at $\lambda=365 \mathrm{~nm}$. Moreover, all compounds present an amine group in the chemical skeleton in order to be used for surface nanoparticle attachment.

After UV irradiation at $\lambda=365 \mathrm{~nm}$, the AgNPs with compound 1 showed a red shift from 410 to $430 \mathrm{~nm}$, and an increase in absorbance at $430 \mathrm{~nm}$ up to $40 \mathrm{~min}$ after UV exposition (see Figure 1A). Similar behavior over time has been reported in previous studies on the nucleation of gold nanoparticles; in these works the abrupt jump in absorbance corresponds with the particle nucleation burst (Chow and Zukoski, 1994; RodríguezGonzález et al., 2007). In the emission spectra, a blue shift from 550 to $521 \mathrm{~nm}$ was observed, as well as an enhancement in the emission intensity at $521 \mathrm{~nm}$ (see Figure 1B). The growth plot also shows a long tail in the range $550-600 \mathrm{~nm}$ after $30 \mathrm{~min}$ (see Figure 1A). This is most likely due to the formation of larger AgNPs aggregates. Interestingly, the maximum emission intensity observed was reached at $40 \mathrm{~min}$. This matches the nucleation burst time as highlighted by the plot of absorbance as a function of time (see Figure 1A).
Nanoparticles stabilized with compound 2,AgNPS@2, showed an increase in the absorbance detected at $420 \mathrm{~nm}$ up to $20 \mathrm{~min}$ after irradiation. However, at values up to $10 \mathrm{~min}$, a new small band at $600 \mathrm{~nm}$ was observed, also revealing the presence of nanoparticle aggregates (see Figure SI1A). Once again, there was an emissive band at $510 \mathrm{~nm}$ (see Figure SI1B).

A similar behavior was obtained for AgNPs@3, with the appearance and increase in the absorbance at $450 \mathrm{~nm}$ and the emission at $490 \mathrm{~nm}$. However, an exposure of longer than $10 \mathrm{~min}$ UV light induced nanoparticle aggregation, as only $10 \mathrm{~min}$ was the best time for nanoparticle formation. Overall nanoparticle formation was confirmed in this case by the greenish emission, and was also detected be the naked eye by the change from colorless to yellow. The yellow color of the dispersion is a strong indication of nanoparticle formation, because it is related to the appearance of the plasmon band in the UV region, which is characteristic of AgNPs. TEM images revealed that the AgNPs obtained were almost spherical.

Average sizes of $10 \pm 1.6,4.0 \pm 0.9$, and $2.8 \pm 0.6 \mathrm{~nm}$, were obtained from TEM images for the AgNPs with additives 1, 2, and 3, respectively, (see Figure 2).

AgNP stability was confirmed by the zeta potential, where the values of $-40 \pm 5 \mathrm{mV},-38 \pm 4 \mathrm{Mv}$, and $-50 \mathrm{mV} \pm 5 \mathrm{mV}$ indicated high stability, for 1,2 , and 3 , respectively. Taking into account the spectral data mentioned above, it was concluded that the additive directly influences nanoparticle formation. This is most likely due to the increasing number of donor atoms, which leads to a displacement in the emission wavelength, as well as an increase in nanoparticle size.

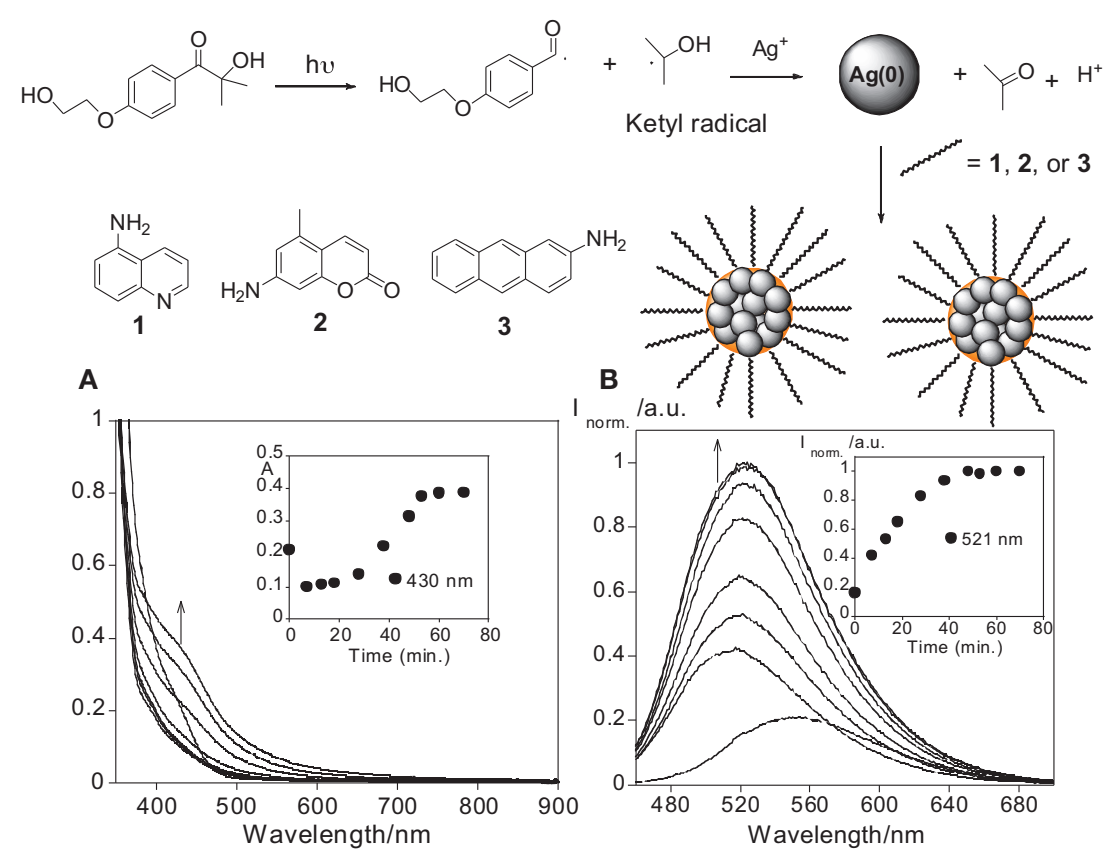

FIGURE 1 | Above: General synthetic pathway of the AgNPs synthesis. Below: (A) Absorption and emission (B) spectra of the AgNPs formation with time containing as additive compound $\mathbf{1}$, in a THF solution, $T=298 \mathrm{~K}, \lambda_{\text {exc }}=430 \mathrm{~nm}$. 

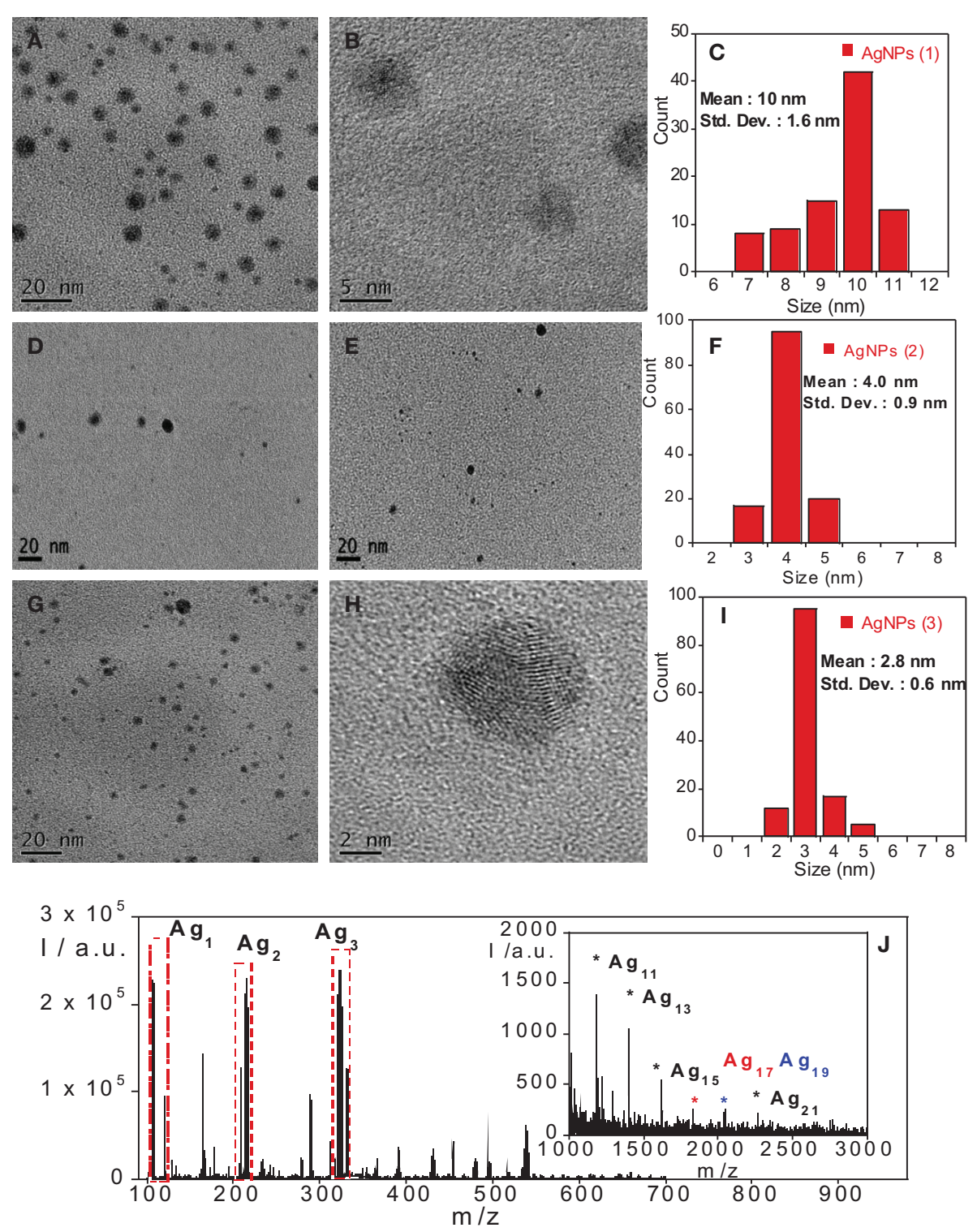

FIGURE $2 \mid(\mathbf{A}, \mathbf{D}, \mathbf{E}, \mathbf{G})$ TEM image of AgNPs with compound $\mathbf{1}$ (A), $2(\mathbf{D}, \mathbf{E})$, and $\mathbf{3}(\mathbf{G})$. (B,H) High-resolution transmition electron microscopy (HRTEM) image of AgNPs with $\mathbf{1}$ (B) and $\mathbf{3}$ (H). Size histogram of nanoparticles with $\mathbf{1}$ (C), $\mathbf{2}$ (F), and $\mathbf{3}$ (I). (J) MALDI-TOF MS spectra of AgNPs with compound $\mathbf{1}$ in THF without matrix.
Figures 2A-I shows the TEM, HRTEM and size histogram of the AgNPs synthetized in this work. The histograms were obtained from multiple TEM images such as those shown in Figure 2. The histograms show a small difference in size distribution, which is due to the different influence of $\mathbf{1}$ to $\mathbf{3}$ additives on the silver nanoparticle fabrication.

The particles shown in Figure 2 are larger than the clusters reported in Maretti's work (Maretti et al., 2009). According to the literature (Liz-Marzán, 2006; Pompa et al., 2006) the collective oscillation of the electrons leads to the appearance of an absorption band, known as a plasmon band. It is well known that the plasmon absorption band does not involve the presence of an emission band, which is why in bare nanometer sized silver particles are not found in any emission band.

The question that now arises is what is the origin of the observed fluorescence in these samples? Some authors have pointed to the presence of silver clusters $\left(\mathrm{Ag}_{n}, n=2-8\right)$ in the samples as the main source of the emission band (Zhang et al., 2005; Vosch et al., 2007). Maretti reports that the clusters are predominantly of type $\mathrm{Ag}_{2}$ and are likely to be supported by larger nanometer sized particles, such as the particles shown in Figure 2. In our case highly emissive AgNPs were also obtained, thus, the emission could be attributed to the formation of small clusters, such as, $\mathrm{Ag}_{2}, \mathrm{Ag}_{3}$, and $\mathrm{Ag}_{4}$ attached to the nanometer 
sized nanoparticles shown in Figure 2. The joining of nanoparticles and clusters on the surface could form a very strong emission ensemble (Maretti et al., 2009; Rao and Pradeep, 2010). Due to the small size of the clusters and their relatively low stability under the electron bean, it is quite difficult to image them by HRTEM.

\section{MALDI-TOF-MS STUDIES}

In order to confirm the clusters hypothesis, we carried out mass spectrometry experiments to demonstrate the presence of $\mathrm{Ag}$ clusters in the samples. In all cases cluster formation was confirmed by MALDI-TOF MS. Peaks at 108.0, 215.2, 322.3, 970.0, $1186.0,1401.9,1617.7,1833.5,2049.3,2265.2 \mathrm{~m} / \mathrm{z}$, corresponding to the species $A g_{1}, A_{2}, A_{3}, A g_{9}, A_{11}, A_{13}, A g_{15}, A g_{17}, A g_{19}$, and $\mathrm{Ag}_{21}$ for compound $\mathbf{1}$ (see Figure 2J) were found. The results also revealed that stabilizers do not affect cluster formation, where the same silver species were found for all the compounds.

\section{Cytotoxicological studies in goldfish}

Depending on their size, AgNPs could permeate through skin and the intestine, and then be accumulated in the liver, lung, blood, kidney, and/or stomach. In order to evaluate the permeation and toxicity of nanoparticles, cytotoxicological studies were performed in vitro in human hepatoma cells and in vivo studies in goldfish (Carassius auratus). The studies in vivo were carried out by analyzing oxidative stress [lipid peroxidation (LPO) and CAT], phase II biotransformation of xenobiotics GST, and histological examination.

Enzymes such as GST or CAT are part of the antioxidant system responsible for the elimination of radicals and molecules produced as a consequence of oxidative stress. The GST is a family of phase II detoxification enzymes that catalyze the conjugation of glutathione (GSH) to a wide variety of endogenous and exogenous electrophilic substances, such as drugs, toxins, and products of oxidative stress, and therefore, they play an important role in preventing oxidative damage (Habig et al., 1974; Hayes et al., 2005). The results of the GST activity measured in the intestines and liver of fish treated with the AgNPs are shown in Figure 3. The GST levels determined in livers were higher than in the intestines. This is because liver is the major metabolic and detoxification organ in living organisms.

The results show a general trend to increase GST activity in injected fish compared to controls. Statistical analysis of the results of GST activity in fish organs (Figure 3I) revealed significant differences $(p<0.05)$ between controls, intestines and livers from fish injected with the AgNPs 3A (diluted in PBS). For fish injected with AgNP 3B (diluted in corn oil) significant differences were found in livers compared to controls. These results suggest that fish injected with AgNPs 3 are subjected to higher oxidative stress than when they are injected with other AgNPs.

In a different study, Chae et al. (Chae et al., 2009) tested two different AgNP dosages in Japanese medaka (Oryzias latipes) and quantified GST (as well as other markers) by measuring the mRNA concentrations in liver extracts. They found that these two AgNPs led to high toxicity thus, causing cellular and DNA damage, as well as carcinogenic and oxidative stresses. In contrast, Kwok et al. (Kwok et al., 2012) showed that different AgNP coatings (citrate, gum Arabic and polyvinylpyrrolidone) influence

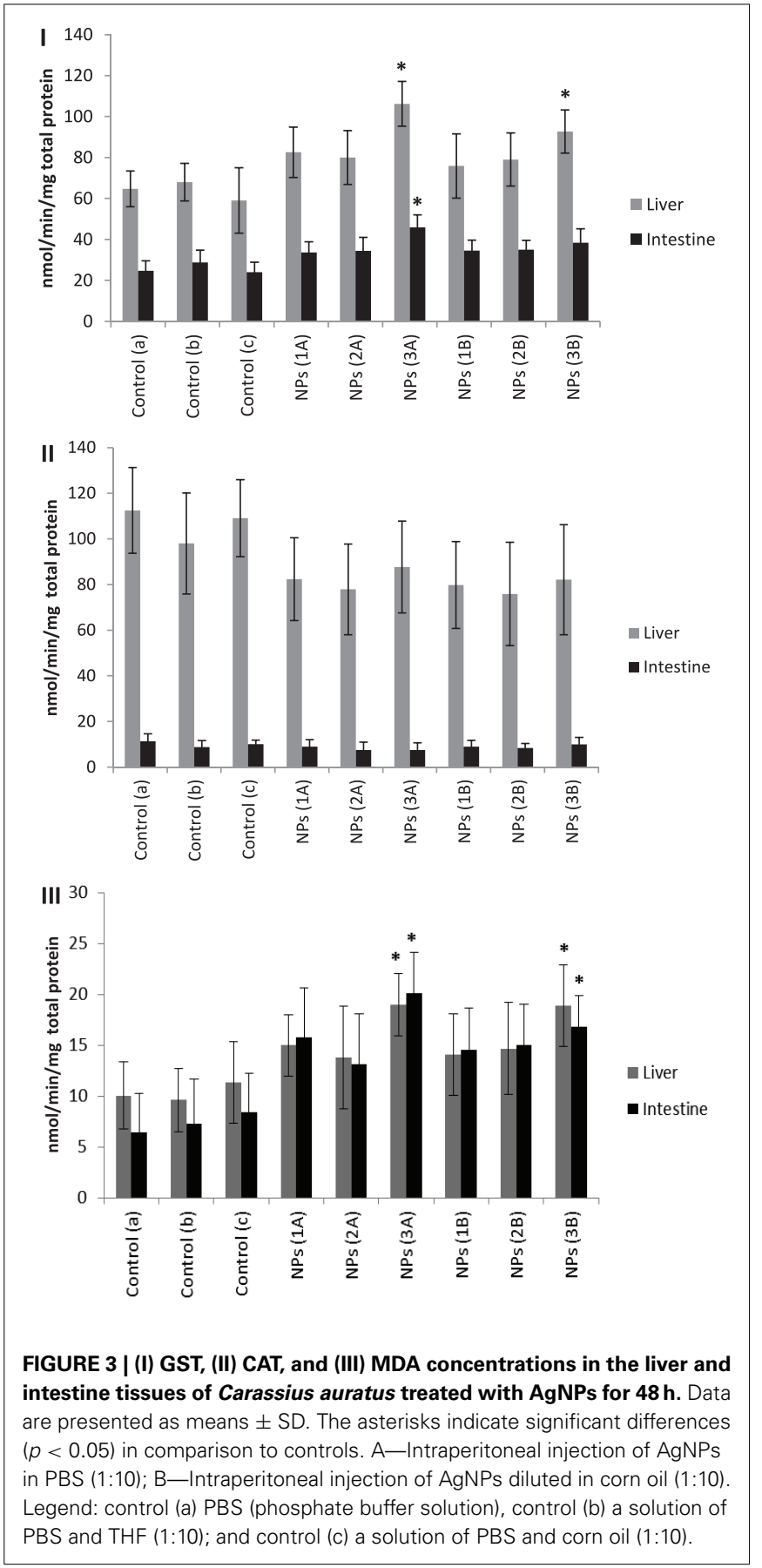

toxicity in the early life of Japanese medaka. Exposure assays showed that citrate and polyvinylpyrrolidone exhibited similar and lower toxicity, however, all the AgNPs coated were three to ten times less toxic than $\mathrm{AgNO}_{3}$.

The decomposition of $\mathrm{H}_{2} \mathrm{O}_{2}$ (Maehly and Chance, 1954) produced in living organisms as a consequence of oxidative stress takes place in a chemical reaction that involves CAT. CAT acts as the catalyst of the reaction. The presence of $\mathrm{Ag}$ (I) ions has been shown to lead to a deformation in Zebrafish embryos, as well as increase in CAT concentration (Choi et al., 2010). In addition, Ag (I) ions are 300 times more toxic to Zebrafish than AgNPs (Scown 
et al., 2010; Powers et al., 2011). On the other hand, no significant CAT response in the hepatocyte cultures of fish exposed to AgNPs was observed (Scown et al., 2010). In our studies no differences were found between injected fish and controls, as shown in Figure 3II.

LPO has been shown to cause various negative effects in terms of cellular integrity in the membranes of the cells (which may lose permeability and function) as well as other changes such as the production of pro-inflammatory agents and potentially toxic substances (Greenberg et al., 2008). LPO is commonly used as an indicator of oxidative stress in cells and tissues (Botsoglou et al., 1994). An increase in LPO in the intestine and livers was observed for the fish injected, as shown in Figure 3III. However, significant differences $(p<0.05)$ were detected only in intestines and livers from fish injected with AgNPs 3A and 3B compared to controls. These results are generally in agreement with GST and CAT results.

Livers from all the controls showed normal histology, while livers from fish injected with AgNPs presented morphological changes varying from subtle to moderate according to the type of AgNP (e.g., tissue degeneration, chromatin condensation, pyknosis) since AgNP 3 cause larger significant changes in livers. No significant changes in tissues were detected by the histological examination of the intestines. However, other authors have found alterations in tissues or cells following exposure to AgNPs (Choi et al., 2010; Farmen et al., 2012).

In order to verify the toxicity of stabilizers 1 to 3 , analysis of oxidative stress measured by GST and CAT activities and LPO (MDA content) as indicator of cell damage were carried out. The intraperitoneal injection of $0,0075 \mathrm{mg} / \mathrm{g}$ fish weight of stabilizers 1-3, diluted in PBS (1:10), from the statistical point of view do not reveal a significant increase in antioxidant enzymes activities for both organs (liver and intestine). However, a trend for antioxidant enzymes and MDA increase was observed in livers from fish injected with stabilizer 3. Thus, the results suggest that the concentrations of compounds injected present no significant toxicity to organisms (see Figure SI2).

Histological observation by epi-fluorescence microscopy showed that there is evidence of nanoparticles in intestine and liver cells, which was revealed by the presence of small fluorescent clusters (Figure 4) suggesting that the AgNPs had penetrated the tissues and cells.
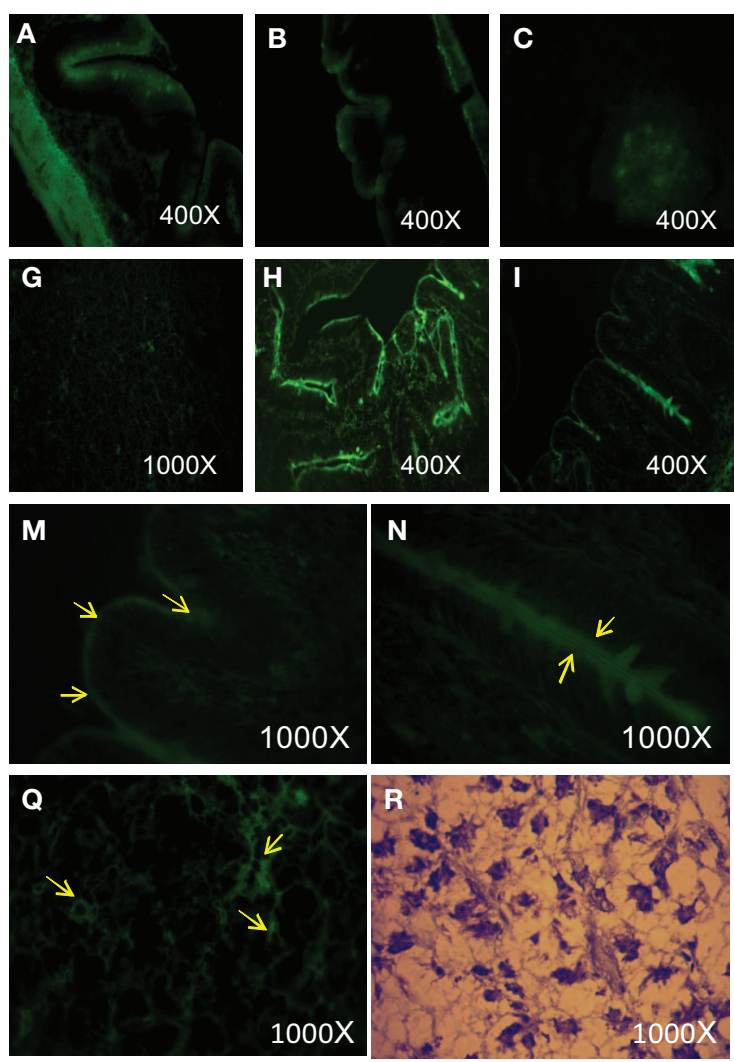

FIGURE 4 | (A,B) AgNPs with compound $\mathbf{1}$ in fish intestine: green fluorescence. THF: In fish intestine (E) and liver (F): no fluorescence visible. (C) AgNPs with compound $\mathbf{1}$ in fish liver: green fluorescence. (D) Bright field optical microscopy of liver (same spot of $\mathbf{C}$ ). (G,L) AgNPs with compound $\mathbf{2}$ in fish liver: green fluorescence. (I,H) AgNPs with compounds $\mathbf{2}$ in fish intestine: green fluorescence. (K,J) Bright
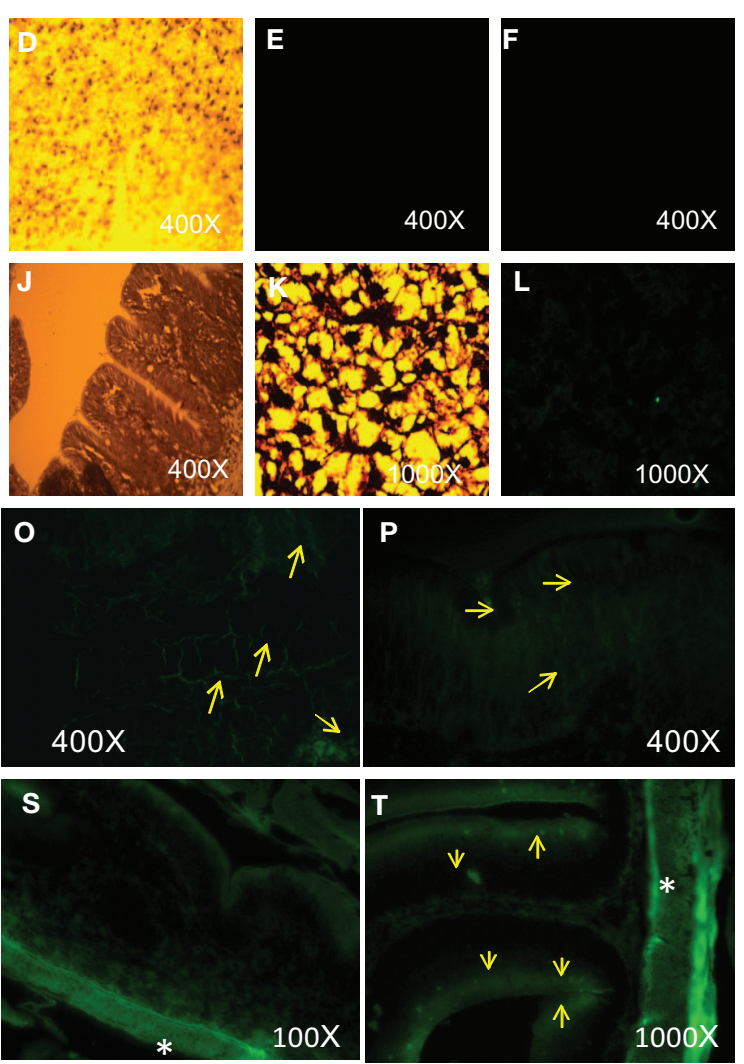

field optical microscopy of liver (K) and intestine (J) (same spot of $\mathbf{G}$ and $\mathbf{I}$, respectively.). (M-P,S,T) AgNPs with compound $\mathbf{3}$ in fish liver: green fluorescence (arrows). (0,R) AgNPs with $\mathbf{3}$ in fish liver: green fluorescence (arrowhead as an example). (R) Bright field optical microscopy of liver (same slide spot of $\mathbf{Q}$ ). $\left({ }^{*}\right)$ The more intense fluorescence at the external muscular layers. 


\section{Dose-dependent cytotoxicity of AgNPs}

The viability of HepG2 cells, after exposure to AgNPs stabilized with compounds 1, 2, and 3, was examined by XTT (Cell Proliferation Assay Kit) assays. The assay measures the amount of XTT reduction by mitochondrial dehydrogenase and assumes that cell viability (corresponding to reductive activity) is proportional to the production of purple formazan which is measured spectrophotometrically. Exponentially divided HepG2 cells were treated with two concentrations ( 25 and $100 \mu \mathrm{g} / \mathrm{ml}$ ) of each AgNP for $72 \mathrm{~h}$, as described in the experimental section. The result from the XTT assay showed that AgNPs differ greatly in their cytotoxic properties depending on their stabilizer compound in a dose-dependent manner (Figure 5).

We found that AgNPs stabilized with compound 1 exerted a cytotoxic effect on HepG2 cells. As shown in Figure 5A, the viability of HepG 2 cells exposed to these particles for $72 \mathrm{~h}$, decreases from $73.4 \%$ at $25 \mu \mathrm{g} / \mathrm{ml}$, to $50.5 \%$ at $100 \mu \mathrm{g} / \mathrm{ml}$, when compared with the control $(p<0.05)$. AgNPs stabilized with compound 3 displayed low toxicity at doses up to $100 \mu \mathrm{g} / \mathrm{ml}$, showing a decrease to $68.0 \%$ in cell viability (Figure 5C). On the other hand, no cytotoxic effect was observed with AgNPs stabilized with compound 2 when up to $100 \mu \mathrm{g} / \mathrm{ml}$ concentration was assayed (Figure 5B).

Since certain nanoparticles have been suggested to interfere with the XTT assay, HepG2 cells were treated with AgNPs stabilized with compounds 1, 2, and 3 at $100 \mu \mathrm{g} / \mathrm{ml}$ and studied under an optical microscope after staining with trypan blue. Captured images of treated cells with AgNPs stabilized with compound 1 showed a high number of non-viable cells (see Figure SI3). Optical images of HepG2 cell treatments with AgNPs stabilized with compounds 2 and 3 did not show significant changes when compared with control cells (Figures SI3C and SI3D), in accordance with the results obtained with the XTT assay (Figure SI3E).

\section{Intracellular location of AgNPs}

To investigate the biodistribution as well as the ability of AgNPs to enter cells, we examined HepG2-treated cells with $100 \mu \mathrm{g} / \mathrm{ml}$ of each AgNP for $24 \mathrm{~h}$ using confocal laser scanning microscopy (CLSM). Using CLSM, AgNPs could be observed directly by their reflection and green emission properties. The nucleus and the cytoplasmatic membrane were stained with DAPI and Cell Mask, respectively. Figure 6 shows the results of in vivo imaging of treated cells with AgNPs stabilized with compound 3. A merge image of all the individual channels and a three dimensional reconstruction shows the presence of individual or agglomerated nanoparticles inside the cells (indicated with white arrows). Similar results were obtained with AgNPs stabilized with compound 2. Due to the cytotoxicity observed in AgNPs stabilized with compound $\mathbf{1}$, it was very difficult to visualize nanoparticles in HepG2 cells when cells were treated for $24 \mathrm{~h}$ at $100 \mu \mathrm{g} / \mathrm{ml}$ of nanoparticle concentration.

As reported, AgNPs can cross the cell membrane via free shuttle or by damaging the membrane integrity through bonding with thiol-containing proteins (You et al., 2012). We demonstrate here that AgNPs stabilized with compounds 2 and $\mathbf{3}$ have the ability to penetrate HepG2 cells, while maintaining their fluorescent properties.

\section{Silver nanoparticle uptake by Flow Cytometry}

To quantify the cellular uptake of AgNPs, flow cytometry analysis of HepG2 cells was performed. Figure SI4 represents the flow cytometry analysis (shown as histograms of the FL1-X-Chanel or auto-fluorescence of the nanoparticles) of control cells and HepG 2 cells incubated with 25 and $100 \mu \mathrm{g} / \mathrm{ml}$ of each AgNP (stabilized with compounds 1, 2, and 3) for $24 \mathrm{~h}$. Results showed an enhancement of cell fluorescence, with a dose-dependent behavior, for the three AgNPs assayed.

\section{CONCLUSIONS}

Using photosynthesized emissive AgNPs containing as additives the organic dyes 5-aminoisoquinoline (1), 7-amino4-methylcoumarin (2), and 2-aminoanthracene (3), in vivo and in vitro toxicological studies were successfully performed. Regarding in vivo studies of oxidative stress, AgNPs with 3 caused larger changes in livers than in intestines with GST level measurements, suggesting the importance of the nanoparticle size in terms of its toxicity. In in vitro studies in HepG2 cancer cells, AgNPs 3 displayed less toxicity by cell viability measurements, whereas the AgNps with 1 were shown to be the most toxic. The higher oxidative stress revealed in AgNPs with 3 in in vivo
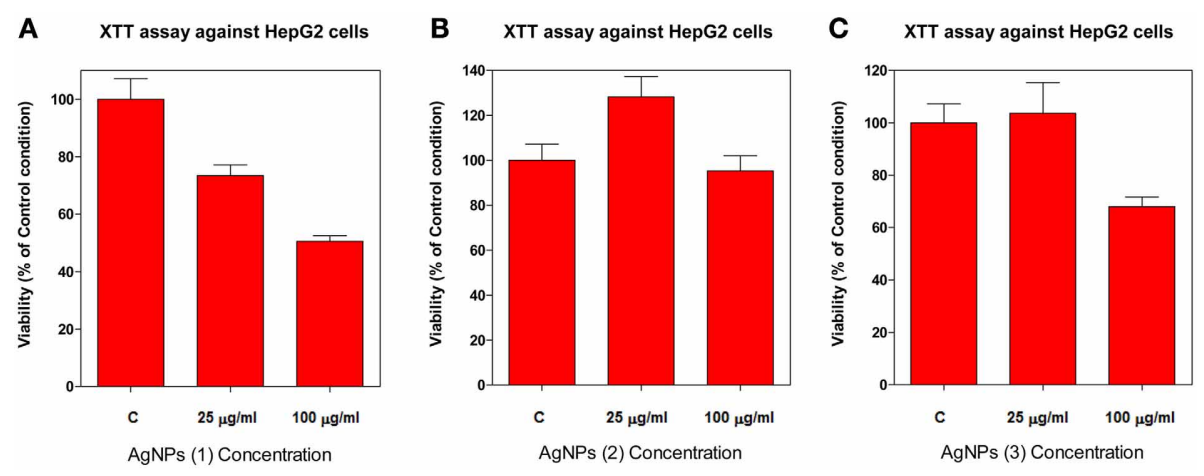

FIGURE 5 | Dose-dependent cytotoxicity of AgNPs against HepG2 cells. The cytotoxic effect of AgNPs against HepG2 cell line was evaluated by the XTT assay. Cell viability was evaluated after $72 \mathrm{~h}$ treatment with two different nanoparticle concentrations (25 and $100 \mu \mathrm{g} / \mathrm{ml}$ ): compound $\mathbf{1}$ (A), compound 2 (B) and compound $\mathbf{3}$ (C) 


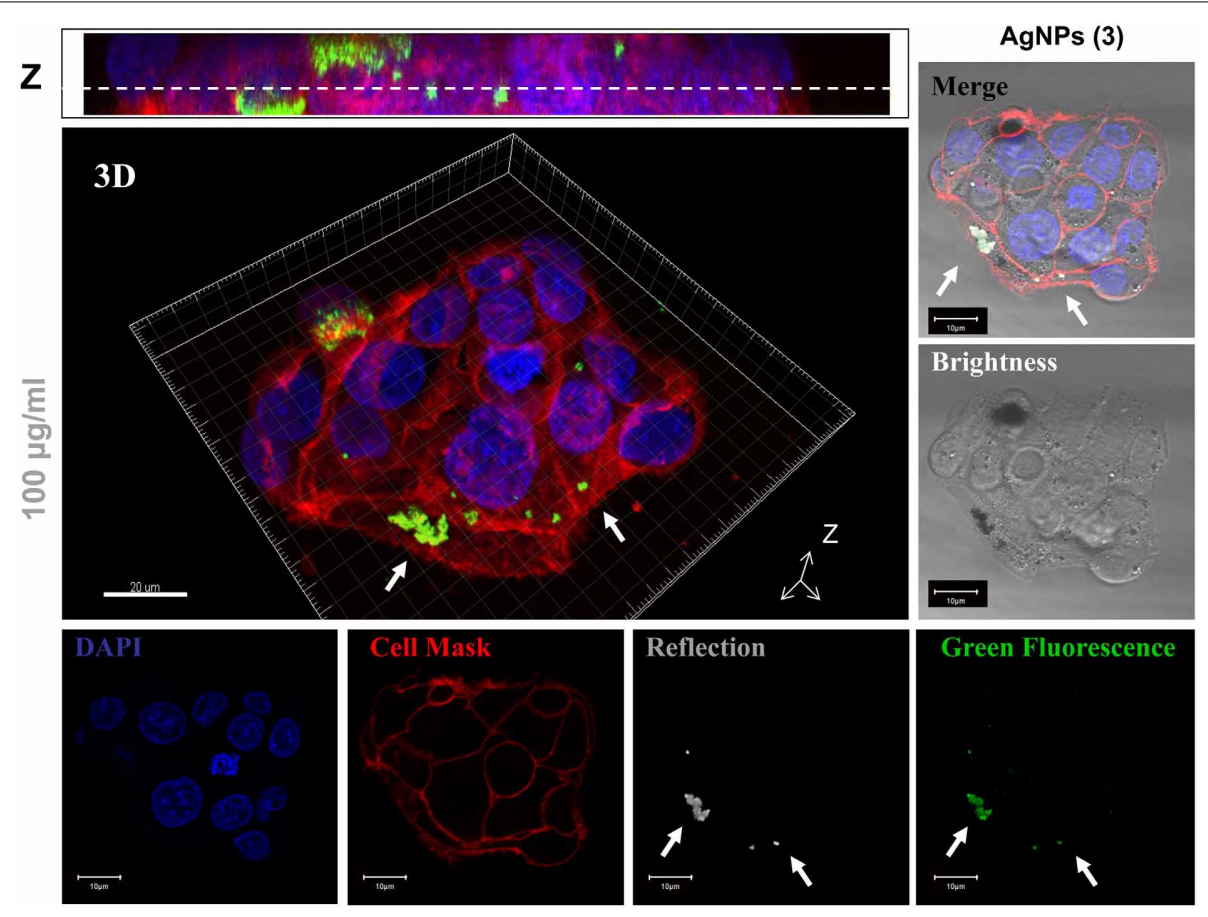

FIGURE 6 | Confocal Laser Scanning Microscopy (CLSM) in vivo images of internalized AgNPs (stabilized with compound 3) in HepG2 cells after $24 \mathrm{~h}$ of treatment at $100 \mu \mathrm{g} / \mathrm{ml}$. Confocal images obtained of a single channels of nanoparticle fluorescence (green fluorescence), nanoparticle reflection brightness (gray), nuclear stain (DAPI), and membrane stain (Cell Mask) are shown. Merge images of all individual channels (merge), three dimensional reconstruction (3D) and $Z$ projection ( $Z$ ) allows to visualize the AgNPs particles into HepG2 treated cells. White arrows indicate the location of internalized AgNPs. studies by GST level, could be related to the nanoparticles and the inner-dye toxicity used as additive. These results highlight the importance of the molecules in the surrounding nanoparticles.

To date results obtained by various research groups have been very variable and depend on the type and nature of AgNPs, the concentration tested, size, route of exposure together with other factors (e.g., aggregation, dissolution) that may influence NP toxicity and difficult inter-study comparisons. For instance, there is the possibility that NP functionalization and mode of delivery influence the presence or absence of Ag (I) ions, which are known to be more toxic than AgNPs themselves.

We found that AgNPs synthesized with additives 1, 2, and 3 were able to penetrate tissues and fish cells, as well as HepG2 cells, and still maintained their own fluorescent properties. These results support the idea that the use of emissive AgNPS for biosciences could be an important nano-tool but safety controls need to be ensured.

\section{AUTHOR CONTRIBUTIONS}

All authors conceived and design the experiments, analyzed the data, contributed to discussion and co-wrote the manuscript. Elisabete Oliveira performed the synthesis of silver nanoparticles and characterization. Benito Rodríguez-González performed the TEM and HRTEM measurements. Mário Diniz performed the in vivo studies, and Javier Garcia-Pardo and Julia Lorenzo the in vitro studies. Carlos Lodeiro and José L. Capelo coordinated and finance the project.

\section{ACKNOWLEDGMENTS}

Authors thank Xunta de Galicia (Biomedicine) for the research grant 10CSA383009PR, and Scientific PROTEOMASS Association (Portugal) for financial support. Elisabete Oliveira and Hugo M. Santos thank to MEC-FCT (Portugal), for the postdoctoral grants SRFH/BPD/72557/2010 and SRFH/BPD/73997/ 2010. Julia Lorenzo thanks to Ministerio de Ciencia e Innovacion (MICINN) of Spain, for grant BIO2010-22321-C02. Authors thank the financial support by REQUIMTE-FCT PEst-C/EQB/ LA0006/2013.

\section{SUPPLEMENTARY MATERIAL}

The Supplementary Material for this article can be found online at: http://www.frontiersin.org/journal/10.3389/fchem.2013. 00029/abstract

Figure SI1 I (A) Absorption and (B) emission spectra of the AgNPs formation with time containing as stabilizer compound 2, in a THF solution, $T=298 \mathrm{~K}, \lambda_{\mathrm{exc}}=430 \mathrm{~nm}$.

Figure SI2 | Intraperitoneal injection of $(0.0075 \mathrm{mg} / \mathrm{g}$ fish weight) of compounds 1, 2, or $3(1 \mathrm{~mL}$ THF diluted to $10 \mathrm{~mL}$ PBS). (I) GST, (II) CAT, and (III) MDA concentrations in the liver and intestine tissues of Carassius auratus treated with $\mathbf{1}, \mathbf{2}$, or $\mathbf{3}$ for $48 \mathrm{~h}$. Data are presented as means $\pm S D$. No statistic significant differences were observed $(p<0.05)$ in comparison to controls (Kruskal-Wallis test; $n=12$ ). Control: PBS (phosphate buffer solution), $n=3$. 
Figure SI3 | Comparative cytotoxicity against HepG2 cells after $72 \mathrm{~h}$ of treatment with AgNPs (stabilized with compounds 1, 2, and 3) at

$\mathbf{1 0 0} \mathbf{~ g} / \mathbf{m l}$. Representative optical microscopy images of control cells (A) and AgNPs treated cells (B-D) are shown. Green and red arrows indicate viable and non-viable HepG2 cells, respectively. Cell viability of HepG2 cells was evaluated by XTT assay (E).

Figure SI4 | Flow cytometric analyses of HEK293-T cells exposed to 25 and $100 \mu \mathrm{g} / \mathrm{ml}$ of AgNPs stabilized with compound 1 (A), compound 2 (B), and compound 3 (C).

\section{REFERENCES}

Aebi, H. (1984). Catalase in vitro. Meth. Enzymol. 105, 121-126. doi: 10.1016/S0076-6879(84)05016-3

Alivisatos, A. P. (1996). Semiconductor clusters, nanocrystals, and quantum dots. Science 271, 933-937. doi: 10.1126/science.271.5251.933

Belser, K., Slenters, T. V., Pfumbidzai, C., Upert, G., Mirolo, L., Fromm, K. M., et al. (2009). Silver nanoparticle formation in different sizes induced by peptides identified within split-and-mix libraries. Agew. Chem. Int. Ed. 48, 3661-3664. doi: 10.1002/anie.200806265

Botsoglou, N. A., Fletouris, D. J., Papageorgiou, G. E., Vassilopoulos, V. N., Mantis, A. J., and Trakatellis, A. G. (1994). A rapid, sensitive, and specific thiobarbituric acid method for measuring lipid peroxidation in animal tissues, food, and feedstuff samples. J. Agri. Food Chem. 42, 1931-1937. doi: 10.1021/jf00045a019

Bradford, M. M. (1976). A rapid and sensitive method for the quantification of microgram quantities of protein utilizing the principle of protein-dye binding. Anal. Biochem. 72, 248-254. doi: 10.1016/0003-2697(76)90527-3

Chae, Y. J., Pham, C. H., Lee, J., Bae, E., Yi, J., and Gu, M. B. (2009). Evaluation of the toxic impact of silver nanoparticles on Japanese medaka (Oryzias latipes). Aquat. Toxicol. 94, 320-327. doi: 10.1016/j.aquatox.2009.07.019

Chau, J. L. H., Hsu, M. K., Hsieh, C. C., and Kao, C. C. (2005). Microwave plasma synthesis of silver nanopowders. Mater. Lett. 59, 905-908. doi: 10.1016/j.matlet.2004.10.068

Choi, J. E., Kim, S., Ahn, J. H., Youn, P., Kang, J. S., Park, K., et al. (2010). Induction of oxidative stress and apoptosis by silver nanoparticles in the liver of adult zebrafish. Aquat. Toxicol. 100, 151-159. doi: 10.1016/j.aquatox.2009.12.012

Chow, M. K., and Zukoski, C. F. (1994). Gold sol formation mechanisms: role of colloidal stability. J. Colloid Interface Sci. 165, 97-109. doi: 10.1006/jcis. 1994.1210

Correia, A. D., Costa, M. H., Luis, O. J., and Livingstone, D. R. (2003). Livingstone, Age-related changes in antioxidant enyzme activities, fatty acid composition, and lipid peroxidation in whole body Gammarus locusta (Crustacea: Amphipoda). J. Exp. Mar. Biol. Ecol. 289, 83-101. doi: 10.1016/S00220981(03)00040-6

Cory, A. H., Owen, T. C., Barltrop, J. A., and Cory, J. G. (1991). Use of an aqueous soluble tetrazolium/formazan assay for cell growth assays in culture. Cancer Commun. 3, 207-212.

Dahl, J. A., Maddux, B. L. S., and Hutchinson, J. E. (2007). Toward greener nanosynthesis. Chem. Rev. 107, 2228-2269. doi: 10.1021/cr050943k

Díez, I., Pusa, M., Kulmala, S., Jiang, H., Walther, A., Goldmann, A. S., et al. (2009). Color tunability and electrochemiluminescence of silver nanoclusters. Angew. Chem. 121, 2156-2159. doi: 10.1002/ange.200806210

Drake, P. L., and Hazelwood, K. (2005). Exposure-related health effects of silver and silver compounds: a review. J. Ann. Occup. Hyg. 49, 575-585. doi: 10.1093/annhyg/mei019

Evanoff, D. D. Jr., and Chumanov, G. (2005). Synthesis and optical properties of silver nanoparticles and arrays. Chemphyschem. 6, 1221-1231. doi: 10.1002/cphc. 200500113

Farmen, E., Mikkelsen, H. N., Evensen, O., Einset, J., Heier, L. S., Rosseland, B. O., et al. (2012). Acute and sub-lethal effects in juvenile Atlantic salmon exposed to low $\mu \mathrm{g} / \mathrm{L}$ concentrations of Ag nanoparticles. Aquat. Toxicol. 108, 78-84. doi: 10.1016/j.aquatox.2011.07.007

Faunce, T., and Watal, A. (2010). Nanosilver and global public health: international regulatory issues. Nanomedicine 5, 617-632. doi: 10.2217/nnm.10.33

Greenberg, M. E., Li, X.-M., Gugiu, B. G., Gu, X., Qin, J., Salomon, R. G., et al. (2008). The lipid Whisker model of the structure of oxidized cell membranes. J. Biol. Chem. 283, 2385-2396. doi: 10.1074/jbc.M707348200
Habig, W. H., Pabst, M. J., and Jakoby, W. B. (1974). Glutathione S-transferases, the first enzymatic step in mercapturic acid formation. J. Biol. Chem. 249, 7130-7139.

Hayes, J. D., Flanagan, J. U., and Jowsey, I. R. (2005). Glutathione transferases. Annu. Rev. Pharmacol. Toxicol. 45, 51-88. doi: 10.1146/annurev.pharmtox.45. 120403.095857

Hussain, S. M., Hess, K. L., Gearhart, J. M., Geiss, K. T., and Schlager, J. J. (2005). In vitro toxicity of nanoparticles in BRL 3A rat liver cells. Toxicol. In Vitro 19, 975-983. doi: 10.1016/j.tiv.2005.06.034

Kiernan, J. A. (2008). Histological and Histochemical Methods. Theory and Practice. 4th Edn. Bloxham, Scion Publishing Ltd.

Kwok, K. W. H., Auffan, M., Badireddy, A. R., Nelson, C. M., Wiesner, M. R., Chilkoti, A., et al. (2012). Uptake of silver nanoparticles and toxicity to early life stages of Japanese medaka (Oryzias latipes): effect of coating materials. Aquat. Toxicol. 120-121, 59-66. doi: 10.1016/j.aquatox.2012.04.012

Landsdown, A. B. G. (2007). Critical observations on the neurotoxicity of silver. Crit. Rev. Toxicol. 37, 237-250. doi: 10.1080/10408440601177665

Lee, P. C., and Meisel, D. (1982). Adsorption and surface-enhanced raman of dyes on silver and gold sols. J. Phys. Chem. 86, 3391-3395. doi: 10.1021/j100214a025

Li, T., Albee, B., Alemayehu, M., Diaz, R., Ingham, L., Kamal, S., et al. (2010). Comparative toxicity study of $\mathrm{Ag}, \mathrm{Au}$, and $\mathrm{Ag}$-Au bimetallic nanoparticles on Daphnia magna. Anal. Bioanal. Chem. 398, 689-700. doi: 10.1007/s00216-0103915-1

Liang, H., Tang, Q., Yu, K., Li, S., and Ke, J. (2007). Preparation of metallic silver from $\mathrm{Ag} 2 \mathrm{~S}$ slurry by direct hydrogen reduction under hydrothermal conditions. Mater. Lett. 61, 1020-1022. doi: 10.1016/j.matlet.2006.06.060

Liz-Marzán, L. M. (2006). Tailoring surface plasmons through the morphology and assembly of metal nanoparticles. Langmuir 22, 32-41. doi: 10.1021/la0513353

Lodeiro, C., Capelo, J. L., Mejuto, J. C., Oliveira, E., Santos, H. M., Pedras, B., et al. (2010). Light and color as analytical detection tools: a journey into the periodic table using polyamines to bio-inspired systems as chemosensors. Chem. Soc. Rev. 39, 2948-2976. doi: 10.1039/b819787n

Luoma, S. (2008). Silver Nanotechnologies and the Environment: Old Problems or New Challenges. Washington, DC: Woodrow Wilson International Center for Scholars Project on Emerging Nanotechnologies or The PEW Charitable Trusts.

Maehly, A. C., and Chance, B. (1954). The assay of catalases and peroxidases. Methods Biochem. Anal. 1, 357-424. doi: 10.1002/9780470110171.ch14

Maretti, L., Billone, P. S., Liu, Y., and Scaiano, J. C. (2009). Facile photochemical synthesis and characterization of highly fluorescent silver nanoparticles. J. Am. Chem. Soc. 131, 13972-13980. doi: 10.1021/ja900201k

Martoja, R., and Martoja, M. (1967). Initiation aux tecniques de l'histologie animal Paris. Masson Cie 1, 345.

Oliveira, E., Genovese, D., Juris, R., Zaccheroni, N., Capelo, J. L., Raposo, M. M. M., et al. (2011a). Bioinspired systems for metal-ion sensing: new emissive peptide probes based on benzo[d]oxazole derivatives and their gold and silica nanoparticles. Inorg. Chem. 50, 8834-8849. doi: 10.1021/ ic200792t

Oliveira, E., Nuñez, C., Rodríguez-González, B., Capelo, J. L., and Lodeiro, C. (2011b). Novel small stable gold nanoparticles bearing fluorescent cysteinecoumarin probes as new metal-modulated chemosensors. Inorg. Chem. 50, 8797-8807. doi: 10.1021/ic200664z

Pastoriza-Santos, I., and Liz-Marzán, L. M. (2008). Colloidal silver nanoplates. State of the art and future challenges. J. Mater. Chem. 74, 1724-1737. doi: 10.1039/b716538b

Pompa, P. P., Martiradonna, L., Della Torre, A., Della Sala, F., Manna, L., De Vittorio, M., et al. (2006). Metal-enhanced fluorescence of colloidal nanocrystals with nanoscale control. Nat. Nanotechnol. 1, 126-130. doi: 10.1038/nnano. 2006.93

Powers, C. M., Slotkin, T. A., Seidler, F. J., Badireddy, A. R., and Padilla, S. (2011). Silver nanoparticles alter zebrafish development and larval behavior: distinct roles for particle size, coating and composition. Neurotoxicol. Teratol. 33, 708-714. doi: 10.1016/j.ntt.2011.02.002

Rao, T. U. B., and Pradeep, T. (2010). Luminescent Ag7 and Ag8 clusters by interfacial synthesis. Angew. Chem. 122, 4017-4021. doi: 10.1002/ange.200907120

Rodríguez-González, B., Mulvaney, P., and Liz-Marzán, L. M. (2007). An electrochemical model for gold colloid formation via citrate reduction. Z. Phys. Chem. 221, 415-426. doi: 10.1524/zpch.2007.221.3.415

Saìnchez-Iglesias, A., Pastoriza-Santos, I., Peìrez-Juste, J., Rodrìguez-Gonzailez, B., Garciìa De Abajo, F., and Liz-Marzaìn, L. (2006). Synthesis and optical 
properties of gold nanodecahedra with size control. Adv. Mater. 18, 2529-2534. doi: 10.1002/adma.200600475

Scown, T. M., Santos, E. M., Johnston, B. D., Gaiser, B., Baalousha, M., Mitov, S., et al. (2010). Effects of aqueous exposure to silver nanoparticles of different sizes in rainbow trout. Toxicol. Sci. 115, 521-534. doi: 10.1093/toxsci/kfq076

Si, S., Dinda, E., and Mandal, T. K. (2007). In Situ synthesis of gold and silver nanoparticles by using redox-active amphiphiles and their phase transfer to organic solvents. Chem. Eur. J. 13, 9850-9861. doi: 10.1002/chem.200701014

Sutherlandm, W. J., Clout, M., Coté, I. M., Daszak, P., Depledge, M. H., Fellman, L., et al. (2010). A horizon scan of global conservation issues for 2010. Trends Ecol. Evol. 25, 1-7. doi: 10.1016/j.tree.2009.10.003

Tam, F., Goodrich, G. P., Johnson, B. R., and Halas, N. J. (2007). Plasmonic enhancement of molecular fluorescence. Nano. Lett. 7, 496-501. doi: 10.1021/ nl062901x

Vosch, T., Antoku, Y., Hsiang, J. C., Richards, C. I., Gonzalez, J. I., and Dickson, R. M. (2007). Strongly emissive individual DNA-encapsulated Ag nanoclusters as single-molecule fluorophores. Proc. Natl. Acad. Sci. U.S.A. 104, 12616-12621. doi: 10.1073/pnas.0610677104

Wong, H. L., Rauth, A. M., Bendayan, R., Manias, J. L., Ramaswamy, M., Liu, Z., et al. (2006). A new polymer-lipid hybrid nanoparticle system increases cytotoxicity of doxorubicin against multidrug-resistant human breast cancer cells. Pharm. Res. 23, 1574-1585. doi: 10.1007/s11095-006-0282-x

You, C., Han, C., Wang, X., Zheng, Y., Li, Q., Hu, X., et al. (2012). The progress of silver nanoparticles in the antibacterial mechanism, clinical application and cytotoxicity. Mol. Biol. Rep. 39, 9193-9201. doi: 10.1007/s11033-012-1792-8
Zhang, J., Xu, S., and Kumacheva, E. (2005). Photogeneration of fluorescent silver nanoclusters in polymer microgels. Adv. Mater. 17, 2336-2340. doi: 10.1002/adma.200501062

Conflict of Interest Statement: The authors declare that the research was conducted in the absence of any commercial or financial relationships that could be construed as a potential conflict of interest.

Received: 25 September 2013; paper pending published: 12 October 2013; accepted: 13 November 2013; published online: 05 December 2013.

Citation: Oliveira E, Santos HM, Garcia-Pardo J, Diniz M, Lorenzo J, RodríguezGonzález B, Capelo JL and Lodeiro C (2013) Synthesis of functionalized fluorescent silver nanoparticles and their toxicological effect in aquatic environments (Goldfish) and HEPG2 cells. Front. Chem. 1:29. doi: 10.3389/fchem.2013.00029

This article was submitted to Inorganic Chemistry, a section of the journal Frontiers in Chemistry.

Copyright (c) 2013 Oliveira, Santos, Garcia-Pardo, Diniz, Lorenzo, RodríguezGonzález, Capelo and Lodeiro. This is an open-access article distributed under the terms of the Creative Commons Attribution License (CCBY). The use, distribution or reproduction in other forums is permitted, provided the original author(s) or licensor are credited and that the original publication in this journal is cited, in accordance with accepted academic practice. No use, distribution or reproduction is permitted which does not comply with these terms. 